Polymer Journal, Vol. 7, No. 4, pp 438-443 (1975)

\title{
Reaction Rate of the Formation of Graft Copolymer by Coupling Reaction
}

\author{
Koji Ishizu, Takashi Fukutomi, and Toshio KakuraI \\ Department of Polymer Technology, Tokyo Institute of Technology, \\ 2-12, Ookayama, Meguro-ku, Tokyo, Japan.
}

(Received November 2, 1974)

\begin{abstract}
Poly(methyl methacrylate) (PMMA) and MMA- $\alpha$-methylstyrene block copolymer were reacted with polystyryl anion in mixed solvents of tetrahydrofuran (THF)-methylcyclohexane at $-78^{\circ} \mathrm{C}$. The changes in the concentration of the living end with the reaction time were measured photometrically. By using the analytical method of successive reactions, the rate constant of each step-wise process $\left(k_{0}, k_{1}, \cdots\right.$, $k_{j}, \cdots, k_{n}$ ), where $k_{j}$ means the rate constant to form the $j$-th branched graft copolymer from the $(j-1)$-th branched graft copolymer, was estimated from the rate constant observed $\left(k_{\mathrm{obs}}\right)$. It was found that $k_{n}$ decreased rapidly with increasing number of polystyrene branches on the PMMA molecule. The tendency of the rate constant to decrease with the progress of the reaction became more clear when the molecular weight of polystyryl anion and the volume fraction of methylcyclohexane increased. These results are discussed in some detail.
\end{abstract}

KEY WORDS PMMA / MMA- $-\alpha$-Methylstyrene Block Copolymer / Polystyryl Anion / Successive Reactions / Rate Constant /

As we noted in a previous report ${ }^{1}$, in the reaction of polystyryl anion (one end) with chloromethylated polystyrene to form the graft copolymer, the reaction ceases to advance when several branches are introduced on the backbone molecule, in spite of the existence of a sufficient residue of the functional groups (chloromethyl and carbanion). It is also well known that the grafting hinders the reactivity of the remaining ester groups. $^{2}$

On the other hand, in a previous paper, ${ }^{3}$ we dealt with the formation of a backbone and a single branch chain (1:1-graft copolymer) by a coupling reaction between PMMA and $\operatorname{poly}(\alpha-$ methylstyryl) anion. We reported that the elution volume of the gel-permeation chromatographs (GPC) of 1:1 graft copolymer was changed, by varying the reaction medium (the ratio of good solvent (THF)-poor solvent (methylcyclohexane)), even when the same degrees of polymerization (DP) of PMMA and poly( $\alpha$-methylstyryl) anion were used. When the dimension of PMMA in solution decreased, the living polymer reacted with the end-pendant group of a backbone polymer. From these results, we have supposed that each ester group on the PMMA molecule does not react with the equal probability. At the first stage of the formation of $1: 1$-graft copolymer, the $\operatorname{poly}(\alpha$-methylstyryl $)$ anion has the tendency to react with the end part of PMMA molecule. It may be anticipated that the steric factors are important in determining the extent of coupling. In order to solve the problems described above, it will be necessary to study them from the kinetic approach.

The details of the rate of reaction of polystyryl anions with PMMA at low temperatures have not been published. The change in the concentration of the living end can be observed photometrically. Generally, the reaction proceeds in a competitive manner successively through the whole reaction system. When we pay attention to one single backbone molecule in this reaction, the coupling proceeds by a successive addition. Then, the rate constants of the successive additions for one backbone molecule, $k_{0}, k_{1}, \cdots, k_{n}$ were estimated from the rate constant observed $\left(k_{\mathrm{obs}}\right)$. On the other hand, we may consider that a $1: 1$ graft copolymer formed in the first stage of reaction has the same structure as an AB-block 
copolymer, as an extreme model. ${ }^{3}$ In order to forecast the rate constant at the second stage of the coupling reaction, the coupling reaction of polystyryl anion with AB-block copolymer was carried out. Coupling reagents were reacted with polystyryl anion in THF-methylcyclohexane mixtures or in THF as solvents at $-78^{\circ} \mathrm{C}$.

\section{EXPERIMENTAL}

PMMA was prepared by the radical polymerization of MMA initiated by $\alpha, \alpha^{\prime}$-azobisisobutyronitrile in acetone at $60^{\circ} \mathrm{C}$ under an atmosphere of nitrogen. After the usual purification, the PMMA obtained was fractionated using acetone (as a good solvent) and methanol (as a nonsolvent). MMA- $\alpha$-methylstyrene block copolymer was prepared by the addition of MMA monomer to poly $(\alpha$-methylstyryl $)$ anion in THF at $-78^{\circ} \mathrm{C}$ in high vacuum. The polymer obtained was then extracted by cyclohexane and acetonitrile for $48 \mathrm{hr}$ each at about $82^{\circ} \mathrm{C}$ to separate the homopolymers. The molecular weight of PMMA prepared by the radical polymerization was calculated by using the following equation. ${ }^{4}$

$$
[\eta]=0.71 \times 10^{-4} M_{w}^{0.73}
$$

The molecular weight of AB-block copolymer was measured by osmotic-pressure measurements in toluene at $37^{\circ} \mathrm{C}$ using a Mechrolab Model 501 Membrane Osmometer. These backbone polymers were reacted with polystyryl anion in THF-methylcyclohexane mixtures or in THF as solvents at $-78^{\circ} \mathrm{C}$. The characteristic absorption maximum of polystyryl anion initiated by cumyl potassium appears at $346 \mathrm{~nm} .{ }^{5}$ Thus the changes in the concentration of living ends can be observed photometrically. In this paper, the concentration of living ends was measured at $400 \mathrm{~nm}$, where the molar extinction coefficient $(\log \varepsilon=3.30)$ is smaller than that at $346 \mathrm{~nm}$, in order to measure even the high concentration of living ends. Figure 1 shows the apparatus used to measure the changes of the concentration of the living ends. $\mathbf{B}$ is the stirring vessel connected to the reaction vessel (A); this part $\mathrm{B}$ can also be kept at the low temperature by maintaining part $\mathrm{C}$ in dry ice-acetone. Part $\mathrm{D}$ was connected to several ampoules of living polymer solution (LP) and an ampoule of backbone polymer solution

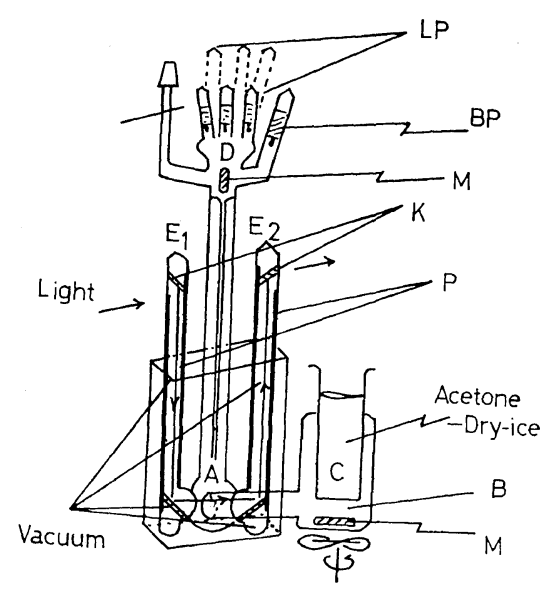

Figure 1. Apparatus to measure the concentration of living ends at $-78^{\circ} \mathrm{C}$ : $\mathrm{M}$, magnet coated with glass; K, mirror; $\mathrm{P}$, bronze tube plated with chromium; LP, solution of polystyryl anion; BP, solution of backbone polymer; $\rightarrow$, the path of the light.

(BP). These solutions were dropped into the reaction vessel (A) through the capillary.

The procedure of measurement was as follows. The solution of the backbone polymer was first introduced into the reaction vessel (A). After the measurement of the transmittance in blank, the apparatus was kept at $-78^{\circ} \mathrm{C}$ for $2 \mathrm{hr}$. Then, the solution of living polymer was introduced into the reaction vessel periodically with vigorous stirring, and the changes in the concentration of living ends as a function of the reaction time were measured photometrically by using a Hitachi 139 UV-VIS Spectrophotometer. In order to determine the structure of the branched copolymer, GPC and the number-average molecular weight (osmoticpressure measurement) of the product were measured. Gel-permeation data were obtained on a Waters Model 200 GPC instrument. Measurements were made in distilled THF at $50^{\circ} \mathrm{C}$ with a three-column system $\left(10^{7}, 10^{6}\right.$, and $\left.10^{5} \AA\right)$ having a flow rate of $1 \mathrm{ml} / \mathrm{min}$. Two $\mathrm{m} l$ of a sample $(0.3 \mathrm{~g} / \mathrm{d} l)$ was injected for $90 \mathrm{sec}$.

\section{Analysis of the Successive Reactions}

From the transmittance-time curves shown in Figure 2, the concentration of the reacted living polymer was read off at an arbitrary time $(t)$. Assuming that this coupling is the secondorder reaction, the rate constant observed $\left(k_{\mathrm{obs}}(t)\right)$ 


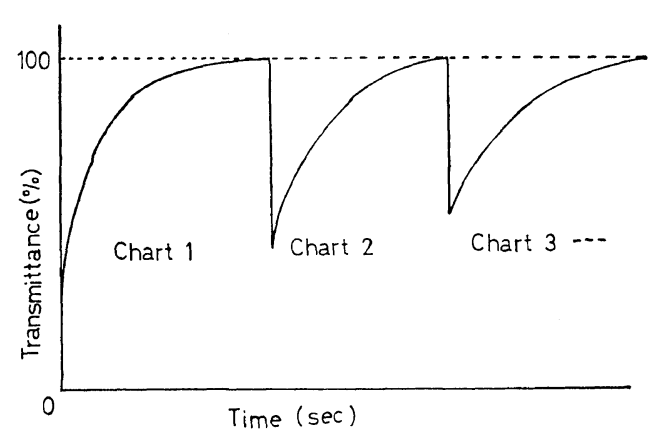

Figure 2. Schematic changes of the transmittance of polystyryl anion as a function of the reaction time.

can be defined from the following equation

$$
k_{\mathrm{obs}}(t)=\frac{\sum_{j=0}^{\infty} k_{j}(t)\left[\mathrm{G}_{j}\right]}{\left[\mathrm{G}_{0}\right]_{0}}
$$

where $\mathbf{G}_{j}, j$-branched graft copolymer

$k_{j}(t)$, the rate constant to form $(j+1)$ branched graft copolymer from $j$ branched graft copolymer at time $(t)$.

$\left[\mathrm{G}_{0}\right]_{0}$, the initial concentration of backbone polymer(mol/l)

$f_{j}(t),\left[\mathrm{G}_{j}\right] /\left[\mathrm{G}_{0}\right]_{0}$ : the mole fraction of $j$ branched graft copolymer at time $(t)$.

The general scheme of grafting can be written as follows.

$$
\mathrm{G}_{0} \underset{k_{0}}{\longrightarrow} \mathrm{G}_{1} \underset{k_{1}}{\longrightarrow} \mathrm{G}_{2} \underset{k_{2}}{\longrightarrow} \mathrm{G}_{3} \underset{k_{3}}{\longrightarrow} \cdots
$$

Estimation of $k_{0}$. From Figure 2, the changes of the concentration of living ends with the time $(t)$ as a parameter are calculated (Figure 3 ). Then, $k_{\text {obs }}(t)$ is plotted against the average number of branches per backbone polymer molecule, within the limits of the average number of branches= about unity (Figure 4). $k_{0}$ is read off by extrapolating $k_{\text {obs }}(t)$ to $t=0$.

Estimation of $k_{1}, k_{2}, \cdots, k_{n}$. In Figure 4, $k_{\text {obs }}(t) v s$. average number of branches is shared out over several points within the range of a few branches and the corresponding $k_{\mathrm{obs}}(t)$ is read off at each point by using eq 3 . From eq 1 , eq 3 can be written as follows.

$$
\begin{aligned}
& k_{\mathrm{obs}}(t)=k_{0} f_{0}(t)+k_{1}(t) f_{1}(t) \\
& f_{0}(t)=\frac{\left[\mathrm{G}_{0}\right]}{\left[\mathrm{G}_{0}\right]_{0}}, \quad f_{1}=\frac{\left[\mathrm{G}_{1}\right]}{\left[\mathrm{G}_{0}\right]_{0}}, \quad \text { and } \\
& f_{0}(t)+f_{1}(t)=1
\end{aligned}
$$

By substituting the values of $f_{0}(t), f_{1}(t)$ (calculated from eq 4) and $k_{0}, k_{1}(t)$ can be calculated. The assumption that there exists no more-than-2branched graft copolymers is correct at the first stage of the reaction. Then the value of $k_{1}$ can be obtained by extrapolating $k_{1}(t)$ to $t=0$. The value of $k_{2}$ can be obtained by the same manner, under the assumption that there exists no morethan-3-branched garft copolymers in the system.

\section{RESULTS AND DISCUSSION}

The reaction conditions for the coupling reaction

\begin{tabular}{|c|c|c|c|c|}
\hline \multirow[b]{2}{*}{ Run } & \multirow{2}{*}{$\begin{array}{c}\mathrm{PMMA}^{\mathrm{b}} \\
{\left[G_{0}\right]_{0}, \mathrm{~mol} / l}\end{array}$} & \multicolumn{2}{|c|}{ Polystyryl anion } & \multirow{2}{*}{$\underset{\text { vol } \%}{\mathrm{MCH}}$} \\
\hline & & $\underset{\mathrm{mol} / l}{\mathrm{Concn}}$ & $M_{w}{ }^{\mathrm{c}}$ & \\
\hline 1 & $8.303 \times 10^{-2}$ & $1.230 \times 10^{-4}$ & $5.3 \times 10^{4}$ & 0 \\
\hline 2 & $1.934 \times 10^{-1}$ & $1.853 \times 10^{-4}$ & $2.0 \times 10^{4}$ & 10.3 \\
\hline
\end{tabular}
of polystyryl anion with PMMA in THF (Run 1) are shown in Table I. Figure 3 shows the

Table I. Reaction conditions for the coupling reactions of polystyryl anion with PMMA ${ }^{2}$

a Solvent, THF or THF-methylcyclohexane; reaction temp, $-78^{\circ} \mathrm{C}$.

b $M_{w}, 5.8 \times 10^{4}$ (by viscometric measurements ${ }^{4}$ )

c By viscometric measurements: $M_{w}, 1.7 \times 10^{5}[\eta]^{1.35}$ in toluene at $30^{\circ} \mathrm{C} .{ }^{6}$

d $\mathrm{MCH}$, methylcyclohexane.

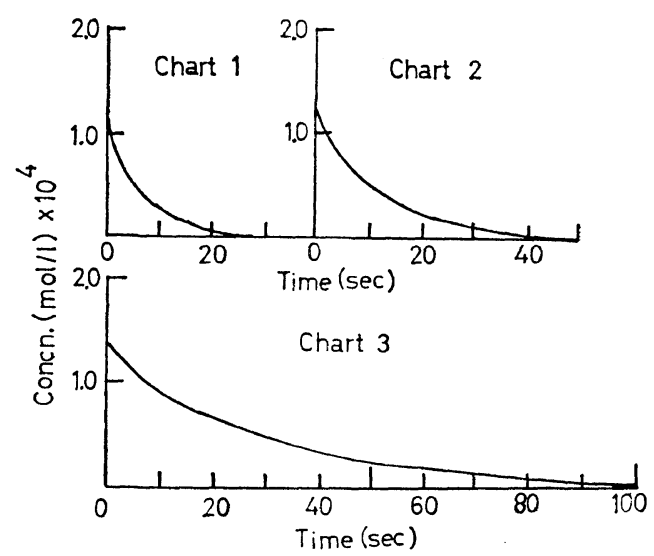

Figure 3. Changes of the concentration of living ends as a function of time $(t)$. 
Table II. Relationship between $k_{\mathrm{obs}}(t)$ and the average number of branches: Run 1

\begin{tabular}{|c|c|c|c|c|c|}
\hline $\begin{array}{c}\text { Average } \\
\text { number of } \\
\text { branches } \\
\text { (number per } \\
\text { backbone } \\
\text { polymer } \\
\text { molecule) }\end{array}$ & 0.094 & 0.234 & 0.487 & 0.769 & 0.939 \\
\hline $\begin{array}{c}k_{\mathrm{obs}}(t), \\
l \mathrm{~mol}^{-1} \mathrm{sec}^{-1}\end{array}$ & $\begin{array}{l}6.60 \\
\times 10^{-1}\end{array}$ & $\begin{array}{l}6.39 \\
\times 10^{-1}\end{array}$ & $\begin{array}{l}5.71 \\
\times 10^{-1}\end{array}$ & $\begin{array}{l}4.81 \\
\times 10^{-1}\end{array}$ & $\begin{array}{l}3.90 \\
\times 10^{-1}\end{array}$ \\
\hline
\end{tabular}

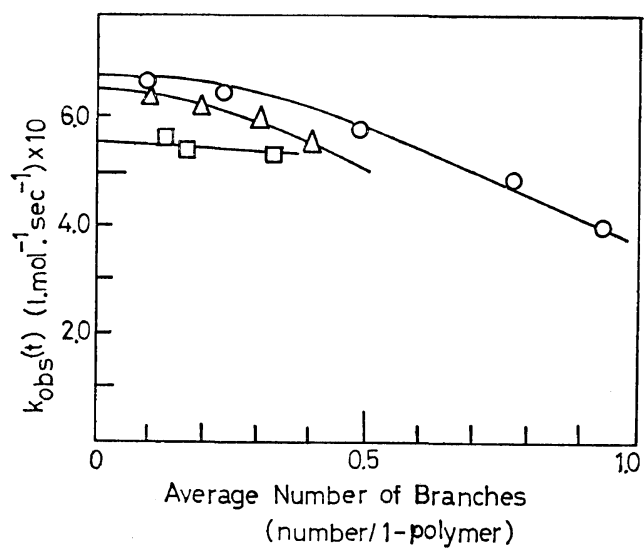

Figure 4. Relationships between $k_{\mathrm{obs}}(t), k_{1}(t)$, and $k_{2}(t)$, and the average number of branches (Run $1): \bigcirc, k_{\mathrm{obs}}(t) ; \triangle, k_{1}(t) ; \square, k_{2}(t)$.

Table III. Relationship between $k_{1}(t)$ or $k_{2}(t)$ and the average number of branches: Run 1

(a)

\begin{tabular}{|c|c|c|c|c|}
\hline $\begin{array}{l}\text { Average } \\
\text { number of } \\
\text { branches } \\
\text { (number per } \\
\text { backbone } \\
\text { polymer } \\
\text { molecule) }\end{array}$ & 0.1 & 0.2 & 0.3 & 0.4 \\
\hline $\begin{array}{c}k_{1}(t) \\
l \mathrm{~mol}^{-1} \sec ^{-1}\end{array}$ & $\begin{array}{l}6.42 \\
\times 10^{-1}\end{array}$ & $\frac{6.22}{\times 10^{-1}}$ & $\begin{array}{l}5.86 \\
\times 10^{-1}\end{array}$ & $\begin{array}{l}5.42 \\
\times 10^{-1}\end{array}$ \\
\hline
\end{tabular}

(b)

\begin{tabular}{cccc}
\hline $\begin{array}{c}\text { Average number } \\
\text { of branches } \\
\text { (number per } \\
\text { backbone } \\
\text { polymer } \\
\text { molecule) }\end{array}$ & 0.13 & 0.15 & 0.33 \\
\hline $\begin{array}{c}k_{2}(t), \\
l \text { mol-1 }^{-1} \mathrm{sec}^{-1}\end{array}$ & $5.62 \times 10^{-1}$ & $5.26 \times 10^{-1}$ & $5.20 \times 10^{-1}$ \\
\hline
\end{tabular}

changes of the concentration of living ends as a function of time. From these conversion curves, the relationship between $k_{\text {obs }}(t)$ and the average number of branches was calculated (see Table II). In Fiugre 4, the relations described in Table II were plotted using the symbol: $\bigcirc$. $k_{0}\left(6.62 \times 10^{-1} l \mathrm{~mol}^{-1} \mathrm{sec}^{-1}\right)$ could be obtained by extrapolating $k_{\mathrm{obs}}(t)$ to $t=0 . \quad k_{\mathrm{obs}}(t)$-average number of branches curves were shared out over several points and the $k_{1}(t)$ values obtained in Table IIIa were plotted using the symbol: $\triangle$ in Figure 4. By extrapolating $k_{1}(t)$ to $t=0, k_{1}(6.43 \times$ $\left.10^{-1} l \mathrm{~mol}^{-1} \mathrm{sec}^{-1}\right)$ could be read off. In the same way, the $k_{2}(t)$ values obtained in Table IIIb were plotted using the symbol: $\square$ in Figure $4 . k_{2}$ was $5.58 \times 10^{-1} l \mathrm{~mol}^{-1} \mathrm{sec}^{-1}$. The slope of $k_{2}(t)$ average number of branches was nearly flat. So, no 4-branched graft copolymers were thought to exist in the system.

PMMA was also reacted with polystyryl anion in $\mathrm{THF}$-methylcyclohexane mixtures, under the reaction conditions shown in Table I (Run 2). Here the molecular weight of PMMA was the same as that used in reaction Run 1, but the molecular weights of the polystyryl anions were different: i.e., Run 1: $M_{w}=5.3 \times 10^{3}$; Run 2: $M_{w}=2.0 \times 10^{4}$. Figure 5 shows the relationships between $k_{\text {obs }}(t), k_{1}(t)$, and $k_{2}(t)$, and the average number of branches. The results of Run 1 and Run 2 are summarized in Table IV. We compared the two experimental series: Run 1 and Run 2. The rate constant obtained in THF

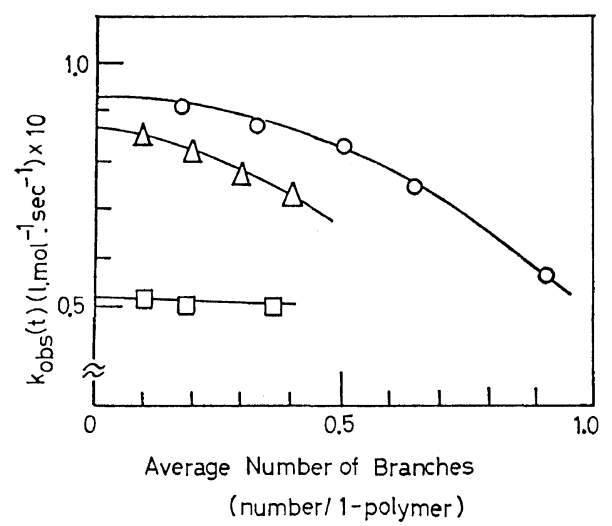

Figure 5. Relationships between $k_{\mathrm{obs}}(t), k_{1}(t)$, and $k_{2}(t)$, and the average number of branches (Run $2): \bigcirc, k_{\mathrm{obs}}(t) ; \triangle, k_{1}(t) ; \square, k_{2}(t)$. 
Table IV. Summary of the rate constants at each stage of the coupling reaction

\begin{tabular}{cccc}
\hline \multirow{2}{*}{ Run } & \multicolumn{3}{c}{ Rate constant, $l \mathrm{~mol}^{-1} \mathrm{sec}^{-1}$} \\
\cline { 2 - 4 } & $k_{0}$ & $k_{1}$ & $k_{2}$ \\
\hline 1 & $6.62 \times 10^{-1}$ & $6.43 \times 10^{-1}$ & $5.58 \times 10^{-1}$ \\
2 & $9.19 \times 10^{-2}$ & $8.58 \times 10^{-2}$ & $5.18 \times 10^{-2}$ \\
3 & $6.89 \times 10^{-2}$ & $5.53 \times 10^{-2}$ & $2.88 \times 10^{-2}$ \\
\hline
\end{tabular}

was about ten times larger than that obtained in THF-methylcyclohexane mixtures. In both media, the rate constants decreased with increasing number of polystyrene branches on the PMMA molecule. In Run $1, k_{1}$ decreased very little in comparison with $k_{0}$, and $k_{2}$ decreased rapidly in comparison with $k_{0}$; the results of Run 2 showed this tendency more clearly. However, the effect of the molecular weight of polystyryl anion on the rate constant cannot be neglected. In a previous paper, ${ }^{3}$ we showed that living polymer reacted with the end-pendant group of a backbone molecule, when the dimensions of the PMMA molecule in solution decreased. From these results, $k_{0}\left(9.19 \times 10^{-2} l \mathrm{~mol}^{-1} \mathrm{sec}^{-1}\right)$ in Run 2 is considered to be the rate constant when polystyryl anion reacted with the end-pendant group of a PMMA molecule at the first stage of the coupling reaction. The graft copolymer molecules formed at the first stage of the reaction have approximately the same structure as ABtype block copolymer. The segment density around the functional groups of AB-type block copolymer has a maximum at the site of the ester group far away from the connecting point of A and B. Therefore, the graft copolymer molecules formed at the second stage are considered to have a structure similar to ABA-type block copolymer, when the length of a backbone polymer molecule in solution decreased. The result that $k_{1}\left(8.58 \times 10^{-2} l \mathrm{~mol}^{-1} \mathrm{sec}^{-1}\right)$ decreased very little in comparison with $k_{0}$ supports the considerations described above. Considering the conformation of a 2-branched graft copolymer similar to ABA-type block copolymer, the pendant groups of a backbone molecule may be hindered by two branches. Therefore, $k_{2}$ decreased rapidly in comparison with $k_{0}$. In order to determine the structure of graft copolymer, GPC of the product (Run 2) was found, as shown in Figure

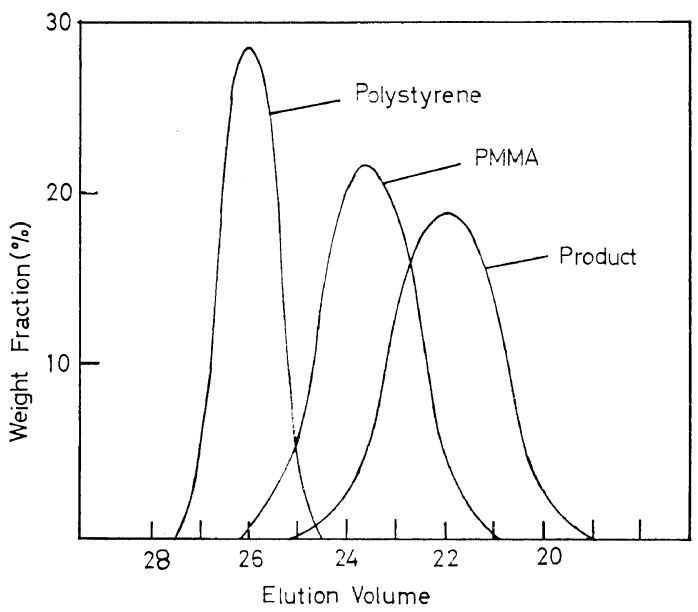

Figure 6. GPC profiles of polystyrene, PMMA, and graft copolymer (Run 2).

Table V. Reaction condition for the coupling reaction of polystyryl anion with MMA$\alpha$-methylstyrene block copolymer ${ }^{\mathrm{a}}$

\begin{tabular}{|c|c|c|c|c|c|}
\hline \multirow{2}{*}{ Run } & \multicolumn{2}{|c|}{$\begin{array}{c}\text { Backbone } \\
\text { polymer }\end{array}$} & \multicolumn{2}{|c|}{ Polystyryl anion } & \multirow{2}{*}{$\begin{array}{c}\mathrm{MCH},{ }^{\mathrm{c}} \\
\mathrm{vol} \%\end{array}$} \\
\hline & $\begin{array}{l}{\left[G_{0}\right]_{0},} \\
\mathrm{~mol} / l\end{array}$ & $M_{n}^{\mathrm{b}}$ & $\begin{array}{c}\text { Concn, } \\
\mathrm{mol} / l\end{array}$ & $M_{w}$ & \\
\hline 3 & $\begin{array}{l}1.749 \\
\times 10^{-1}\end{array}$ & ${ }^{7.26} \times 10^{4}$ & $\begin{array}{l}1.880 \\
\times 10^{-4}\end{array}$ & $2.0 \times 10^{4}$ & 10.4 \\
\hline
\end{tabular}

a Solvent, THF-methylcyclohexane; reaction temp, $-78^{\circ} \mathrm{C}$.

b MMA part, $4.70 \times 10^{4} ; \quad \alpha$-methylstyrene part, $2.56 \times 10^{4}$.

c $\mathrm{MCH}$, methylcyclohexane.

6. It is seen that the elution peak of the product shifts the position of high molecular weight in comparison with the initial PMMA. The number-average molecular weight measured by osmotic pressure measurements was $1.62 \times 10^{5}$, and the average number of branches was 5.2. The average number of branches computed from photometrical measurements was 5.0 , on the assumption that the coupling reaction between PMMA and polystyryl anion has taken place as expected. These values agree very well.

Finally, the reaction condition for the coupling reaction of polystyryl anion with $\mathrm{MMA}-\alpha-$ methylstyrene block copolymer in THF-methylcyclohexane mixtures is shown in Table $\mathrm{V}$ (Run 3). The relationships between $k_{\mathrm{obs}}(t), k_{1}(t)$, and 


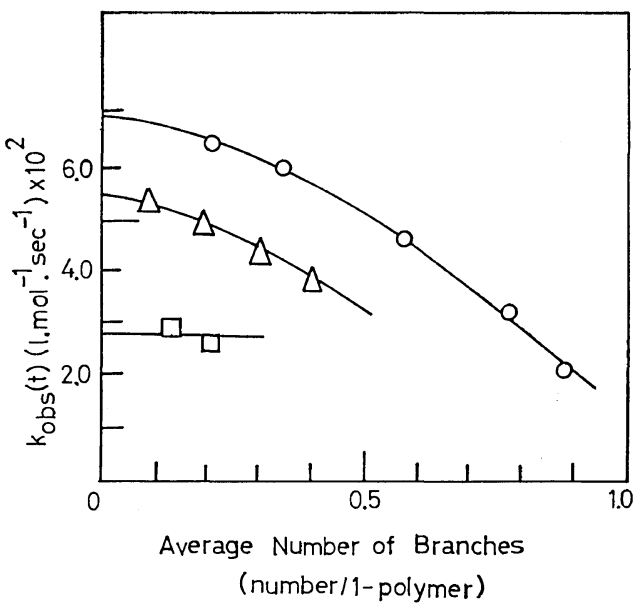

Figure 7. Relationships between $k_{\mathrm{obs}}(t), k_{1}(t)$, and $k_{2}(t)$ and the average number of branches (Run 3): $\bigcirc, k_{\mathrm{obs}}(t) ; \triangle, k_{1}(t) ; \square, k_{2}(t)$.

$k_{2}(t)$, and the average number of branches are shown in Figure 7. The rate constants of $k_{0}$, $k_{1}$, and $k_{2}$ are summarized in Table IV. MMA part of AB-type block copolymer was $4.7 \times 10^{4}$ and is about the same molecular weight as that of the PMMA $\left(M_{w}=5.8 \times 10^{4}\right)$ used in Run 2 . $\alpha$-methylstyrene part of AB-type block copolymer was $2.56 \times 10^{4}$ and is about the same molecular weight as that of the polystyryl anion used in Run 3. $k_{0}\left(6.89 \times 10^{-2} l \mathrm{~mol}^{-1} \mathrm{sec}^{-1}\right)$ in Table IV is considered to express the rate constant at the second stage of the reaction, corresponding to the case that the grafting sites are fixed only at the end-pendant groups of a PMMA molecule at the first stage. This value was smaller than that of $k_{1}\left(8.58 \times 10^{-2} l \mathrm{~mol}^{-1} \mathrm{sec}^{-1}\right)$ of Run 2 . However, the rate constants of both reactions (Run 2 and Run 3 ) at the third stage agreed well. $k_{2}\left(2.88 \times 10^{-2} l \mathrm{~mol}^{-1} \mathrm{sec}^{-1}\right)$ of Run 3 means the rate constant at the fourth stage of the coupling reaction. The value of $k_{2}$ showed an extreme decay. These tendencies, i.e., the progressively decreasing rate constants of the addition, $k_{0}, k_{1}, k_{2}, \ldots$ with increasing number of polystyrene branches on the PMMA molecule, are considered to correspond to the hindering effects of branches around the functional groups on a backbone molecule. A theoretical treatment, considering that the main factor for hindering effects is the segment density around the functional groups, will be reported in the near future.

\section{REFERENCES}

1. K. Ishizu, T. Fukutomi, and T. Kakurai, Polymer J., 7, 228 (1975).

2. G. Finaz, Y. Gallot, J. Parrod, and P. Rempp, J. Polym. Sci., 58, 1363 (1962).

3. K. Ishizu, T. Fukutomi, T. Kakurai, and T. Noguchi, Polymer J., 4, 105 (1973).

4. S. Chinai, J. Matlack, A. Resnick, and R. Samuels, J. Polym. Sci., 17, 391 (1955).

5. R. Asami, M. Levy, and M. Szwarc, J. Chem. Soc., 361 (1962).

6. T. Fujimoto, N. Ozaki, and M. Nagasawa, $J$. Polym. Sci., Part A, 3, 2259 (1965). 